\title{
Cazenave, María Eugenia et al. (2016). \\ MANUAL DE INFORMÁTICA APLICADA A LA TRADUCCIÓN \\ Reseña: Ana Belén Martínez López \\ Universidad de Córdoba
}

Autores: Cazenave, María Eugenia et al. (2016).

Editorial: Editorial del CTPBA (Colegio de Traductores Públicos de la Ciudad de Buenos Aires)

Reseña: Ana Belén Martinez López. (Universidad de Córdoba)

Número de páginas: 279 páginas

ISBN: 978-987-1763-18-4

FECHA DE RECEPCIÓN: 10/10/2016

FECHA DE ACEPTACIÓN: 20/12/2016

PÁGINAS: 467-468

Una obra esta imprescindible para la formación de traductores en nuestros días. El Colegio de Traductores Públicos de la Ciudad de Buenos Aires ha acertado con promover la aparición de una obra de esta naturaleza, que redunda en la capacitación tecnológica e informática de nuestros futuros egresados en Traducción e Interpretación.

La problemática a una y otra orilla del Atlántico es similar, con la diferencia de que en Argentina, por lo que exponen los autores en la contraportada, «en ese momento, la obra venía a echar un poco de luz sobre un tema del cual ya se hablaba mucho en el país, pero que no formaba parte de casi ningún plan de estudio de los traductorados».

En Europa, en general, y en España, en particular, el debate sobre el papel de la Informática Aplicada a la Traducción no lo pone en duda casi nadie y es cierto que, a día de hoy, todos los planes de Estudios del Grado en Traducción e Interpretación en Universidades españolas incorpora una o varias asignaturas que versan precisamente sobre los recursos informáticos que necesita conocer el futuro egresado en Traducción para el ejercicio profesional como traductor.

Quizás, y en eso las cosas son muy similares en Argentina y España, el debate de fondo reside en cuánta importancia relativa hay que acordar a la formación en Informática aplicada a la Traducción y cuánta a la formación más tradicional de traductores, con o sin recursos tecnológicos a la vista. En esto no hay acuerdo y el debate sigue vivo entre las tendencias más conservadoras que reivindican la enseñanza-aprendizaje de la traducción como se ha venido haciendo tradicionalmente desde la segunda mitad del siglo XX y aquellos que, situados en las antípodas de los primeros, reivindican ante todo una capacitación tecnológica de los traductores, prestando más o menos importancia al propio proceso tradicional de «traducción», que es lo que al final hace un traductor, apoyado o no en herramientas o recursos de una u otra naturaleza.

Otro debate que también se plantea en nuestros días es el cambio de paradigma que se está operando en la práctica translativa con la irrupción de la Traducción Automática (TA) de forma cada vez más importante, y, por ende, de la conversión del traductor en revisor de lo que ha sido traducido previamente por la máquina. Hablamos de esa profesión relativamente reciente que denominamos «postedición humana», que no viene a ser más que una especialización en revisión de textos, con la diferencia de que los textos que son objeto de revisión en lugar de haber sido generados por otro traductor han sido producidos por un sistema informático de Traducción Automática.

Todos estos temas, desde la Ofimática hasta la Traducción Automática, pasando por las distintas herramientas y recursos al uso en la práctica de la traducción profesional son objeto de estudio en este magnífico manual de introducción a la Informática, pensado para traductores en formación, y yo me atrevería a decir que también para aquellos que todavía dudan entre lo analógico y lo digital. 
La tecnología está aquí, y transforma nuestra profesión, ampliando también el volumen de textos que son objeto de traducción año a año y de forma exponencial, por mor de la internacionalización y la globalización en la que vivimos inmersos. Repito, la tecnología está aquí y ha venido para quedarse. Y corresponde a docentes e investigadores seguir formando magníficos traductores con el apoyo de esta, no en su contra. Al menos esa es mi modesta opinión, como profesora que soy precisamente de Informática Aplicada a la Traducción en la Universidad de Córdoba (Andalucía), aunque no sea este el único ámbito al que dedico mi actividad docente en esta Universidad.

Entrando en materia sobre el contenido que se recoge en este pertinente y valioso manual, he de decir que se encuentra dividido en trece capítulos, que van haciendo un recorrido por lo más básico (la distinción entre hardware y software o la descripción de los sistemas operativos) hasta adentrarse en el estudio y descripción pormenorizada de las distintas herramientas y recursos que constituyen el entorno de trabajo habitual del profesional de la traducción en nuestros días.

Vamos a entrar, en primer lugar, en la enumeración de esos capítulos, para acto seguido, hacer alguna apreciación sobre los temas que se abordan en cada uno de ellos.

Capítulo 1. Introducción al hardware y al software

Capítulo 2. Sistemas operativos

Capítulo 3. Mantenimiento de nuestro equipo

Capítulo 4. Suites ofimáticas

Capítulo 5. Memorias de traducción

Capítulo 6. Gestión de terminología

Capítulo 7. Alineación

Capítulo 8. Control de calidad bilingüe y monolingüe

Capítulo 9. Otras herramientas para traductores

Capítulo 10. Recursos tecnológicos en internet

Capítulo 11. Desktop Publishing (DTP)

Capítulo 12. Aplicaciones móviles

Capítulo 13. Traducción Automática

Se podría decir que este manual va más allá de una mera presentación de herramientas para la traducción y se adentra en la presentación de recursos para la consulta terminológica, la gestión de la terminología, la localización y el uso de recursos documentales y tecnológicos, entre otros temas de interés.

Todo un acierto hacer una publicación de este tipo, sobre todo porque acota lo que para los autores debe resultar indispensable para cualquier traductor en nuestros días y lleva de la mano al aprendiz desde lo más simple hasta lo más complejo, sin dejar de lado ningún ámbito relevante de esta disciplina relacionada con el ámbito de la Traducción.

También es digna de mención, en este caso, la edición de la obra a todo color y con una presentación muy cuidada. 